Trends Endocrinol Metab. 2012 November ; 23(11): 576-581. doi:10.1016/j.tem.2012.03.008.

\title{
Estrogen and the Skeleton
}

Sundeep Khosla, M.D., Merry Jo Oursler, Ph.D., and David G. Monroe, Ph.D. Endocrine Research Unit and Kogod Center on Aging, Mayo Clinic and Foundation, Rochester, Minnesota 55905, USA

\begin{abstract}
Estrogen is the major hormonal regulator of bone metabolism in women and men. Therefore, there is considerable interest in unraveling the pathways by which estrogen exerts its protective effects on bone. While the major consequence of the loss of estrogen is an increase in bone resorption, estrogen deficiency is associated with a gap between bone resorption and formation, indicating that estrogen is also important for maintaining bone formation at the cellular level. Direct estrogen effects on osteocytes, osteoclasts, and osteoblasts lead to inhibition of bone remodeling, decreased bone resorption, and maintenance of bone formation, respectively. Estrogen also modulates osteoblast/osteocyte and T-cell regulation of osteoclasts. Unraveling these pleiotropic effects of estrogen may lead to new approaches to prevent and treat osteoporosis.
\end{abstract}

\section{Overview of estrogen action on bone}

Since the seminal observations by Fuller Albright 70 years ago that estrogen deficiency in women is associated with bone loss and osteoporosis (1), considerable clinical and basic research has now established that estrogen is perhaps the major systemic regulator of bone metabolism not only in women, but also in men (2). Lindsay and colleagues (3), over 35 years ago, demonstrated prevention of bone loss by estrogen in oophorectomized women, and treatment with the synthetic estrogen mestranol completely prevented decreases in metacarpal mineral content over 5 years. The past several decades have witnessed a growing understanding of the mechanisms by which estrogen regulates bone metabolism, and this perspective summarizes our current understanding of estrogen action on bone, principally as it pertains to the adult skeleton.

Given the key role of estrogen in regulating bone metabolism in women, it had generally been assumed that, analogous to estrogen, testosterone was the dominant sex steroid regulating bone metabolism in men. However, an increasing body of evidence, beginning in the mid-1990's [summarized in (4)], has now established that even in men, estrogen remains the major regulator of bone. The definitive study examining the relative contributions of testosterone versus estrogen towards regulating bone metabolism in men was conducted by Falahati-Nini et al. (5) who used an experimental design in which sex steroid production was suppressed in adult men by a combination of a GnRH agonist and an aromatase inhibitor, followed by selective replacement of either estrogen or testosterone, both, or neither, by placing the men on the respective patches. After baseline measurements of bone turnover

\footnotetext{
(C) 2012 Elsevier Ltd. All rights reserved

Address all correspondence to Sundeep Khosla, M.D., Mayo Clinic, 200 First Street SW, Guggenheim 7, Rochester, MN 55905. Phone: (507) 255-6663, Fax: (507) 293-3853, khosla.sundeep@ mayo.edu..

Publisher's Disclaimer: This is a PDF file of an unedited manuscript that has been accepted for publication. As a service to our customers we are providing this early version of the manuscript. The manuscript will undergo copyediting, typesetting, and review of the resulting proof before it is published in its final citable form. Please note that during the production process errors may be discovered which could affect the content, and all legal disclaimers that apply to the journal pertain.
} 
markers, the men were randomized to 4 different groups in order to rigorously delineate the relative contributions of estrogen and testosterone towards regulating bone turnover. At the end of the study, highly statistically significant results showed that estrogen accounted for $70 \%$ or more of the total effect of sex steroids on bone resorption in these older men, while testosterone could account for no more than $30 \%$ of the effect. These findings, combined with observations from numerous other clinical-investigative studies [summarized in (4)], have now established that estrogen is a key hormonal regulator of bone metabolism not only in women, but also in men.

Despite the critical importance of estrogen for bone, it has proven to be remarkably challenging to define the precise mechanism(s) by which estrogen regulates bone metabolism. At the clinical level, treatment of postmenopausal women with estrogen leads to a marked and sustained reduction in urine or serum markers of bone resorption (6). Changes in bone formation markers are more complex: there is a transient increase, followed by a sustained decrease (6). Bone biopsy data, which is generally obtained months or years after starting estrogen replacement, correlate well with the bone marker data, with a reduction in indices of bone resorption (osteoclast [see Glossary] numbers, percent eroded surface) and bone formation (osteoblast numbers, bone formation rates) (7). Withdrawal of estrogen (as in oophorectomy or menopause) leads to exactly the opposite changes: a marked increase in bone resorption and a coupled increase in bone formation indices (surrogate serum/urine markers and by histology) (8). However, the increase in bone resorption following estrogen deficiency outstrips the increase in bone formation, leading to net bone loss.

Based on these fundamental clinical observations, basic research attempting to define the skeletal actions of estrogen has focused on defining how estrogen (a) inhibits bone resorption and (b) regulates bone formation. The latter is particularly challenging since, as noted above, estrogen treatment results overall in a decrease in bone formation, while chronic estrogen deficiency is associated with increased bone formation. And yet, early after initiating estrogen therapy, there is a transient increase in bone formation before the subsequent decrease. The complexity of this problem can be summarized as follows: estrogen deficiency results in an increase in bone formation, but there is a relative deficit in bone formation as compared to bone resorption. With this issue in mind, the subsequent sections summarize our current mechanistic understanding of estrogen effects on bone resorption and formation. Prior to doing so, however, it is important to briefly review the fundamental mechanisms of bone remodeling and the key role of the osteocyte in regulating bone turnover.

\section{The bone remodeling compartment and central role of the osteocyte}

In order to maintain structural integrity, the skeleton needs to constantly remodel and repair the microcracks that develop both in cancellous bone, the "spongy" bone present in the vertebrae, pelvis, and metaphyses of long bones, and in cortical bone, the compact bone present in the diaphysis of the long bones and surrounding the cancellous bone in the vertebrae and pelvis. This remodeling process occurs in basic multicellular units (BMUs) which include osteoclasts, osteoblasts, and osteocytes within the bone remodeling cavity (Figure 1). Recent work has demonstrated that the BMU is covered by a "canopy" of cells (most probably bone-lining cells) that form the bone remodeling compartment (BRC) and seem to be connected to bone-lining cells on the quiescent bone surface $(9,10)$. In turn, these bone lining cells are in communication with osteocytes embedded within the bone matrix (10). The canopy cells are also in close proximity to capillaries which may serve as a conduit for cells needed in the BMU. 
Osteocytes play a key role in controlling bone remodeling. Osteocytes sense mechanical strain and the developing microcracks, respond to hormonal changes, such as estrogen deficiency, and are able to trigger bone remodeling, most likely via communication with bone-lining cells (11). Bone remodeling begins by the initiation of bone resorption by osteoclasts, and consistent with the critical role of osteocytes in this process, recent studies have demonstrated that they represent an important source of receptor activator of $\mathrm{NF} \kappa \mathrm{B}$ ligand (RANKL) in bone $(12,13)$, although it is likely that other cells in the bone microenvironment also contribute to the pool of available RANKL that regulates osteoclastogenesis (14). RANKL is the key molecule needed for osteoclast development from myeloid precursors, and it is likely that the initiation of bone resorption by osteocytes involves a RANKL-mediated mechanism.

As alluded to earlier, a fundamental concept of bone remodeling is that of "coupling" between bone resorption and bone formation. Thus, once osteoclasts have completed their work of bone resorption (for example, clearing away a microcrack in bone), they recruit osteoblasts via a number of potential mechanisms to refill the resorbed cavity and thereby maintain the overall integrity and strength of the skeleton. Although this is clearly an evolving area, there appear to be two fundamental mechanisms for osteoclastic recruitment of osteoblasts: first, osteoclastic bone resorption leads to the release of growth factors from the bone matrix which, in turn, increase osteoblast number, differentiation, and/or activity. To date, transforming growth factor beta (TGF $\beta$ ) has been identified most convincingly as one such "coupling" growth factor (15), but other candidates include insulin-like growth factor I and II (IGF-I and -II), as well as bone morphogenetic proteins (BMPs) (16). Second, osteoclasts appear to directly regulate osteoblasts both via cell-cell contact and by secreted factors. To date, ephrinB2, a transmembrane protein expressed on osteoclasts and its engagement with its receptor, EphB4, on osteoblasts, leading to bi-directional signaling between these cells, is one of the cell-cell contact mechanism mediating cross-talk between these cells. Binding of ephrinB2 to EphB4 leads to a suppression of osteoclastic activity and enhances osteoblastic differentiation (17); however, further studies are needed to define the extent to which ephrinB2-EphB4 signaling in osteoblastic cells results in the coupling of bone formation to bone resorption. Moreover, recent studies have also found that mature osteoclasts may also negatively regulate bone formation (18). Thus, osteoclasts have been shown to express semaphoring 4D (Sema4D, previously shown to be an exon guidance molecule). Binding of Sema4D to its receptor, Plexin-B1, on osteoblasts leads to an inhibition of osteoblastic activity and bone formation.

Mature osteoclasts also secrete a number of osteoblast simulatory factors, including the secreted signaling molecules Wnt10b, BMP6, and the signaling sphingolipid, sphingosine-1phosphate (19); these factors, along with other, as yet unknown secreted factors, serve to increase osteoblast number and/or activity. This coupling of bone resorption to bone formation explains, at least in part, why decreases in bone resorption are generally followed by parallel decreases in bone formation. As noted above, estrogen treatment leads to a rapid decrease in bone resorption followed by a somewhat later decrease in bone formation. Other drugs that inhibit bone resorption, such as bisphosphonates (20) or an antibody to RANKL (21) lead to similar decreases in bone formation.

Given the central role of the osteocyte in regulating the activation of bone remodeling and bone resorption, a logical question is whether this is the key estrogen target cell in bone? Tomkinson et al. (22) initially demonstrated that estrogen deficiency induced by GnRH treatment in premenopausal women leads to a 4-fold increase in osteocyte apoptosis in bone biopsy samples, as assessed by the percentage of osteocytes displaying DNA breaks using an in situ nick translation technique. Subsequently, these investigators confirmed these findings in rats, showing that ovariectomy results in similar, 4-fold increases in osteocyte 
apoptosis in cancellous and cortical bone in the tibia (23). The biological relevance of the osteocyte apoptosis following estrogen deficiency was demonstrated in a more recent study by Emerton et al. (24) where treatment of ovariectomized mice with a pan-caspase inhibitor prevented the increase in osteocyte apoptosis present in the cortical bones of untreated, ovariectomized mice and also prevented the increase in osteoclastic bone resorption on endocortical surfaces normally observed following ovariectomy. A limitation of this study, however, was that the investigators did not report on changes occurring in cancellous bone.

In vitro studies using MLO-Y4 osteocyte-like cells have demonstrated that $17 \beta$-estradiol can prevent etoposide-induced apoptosis of these cells (25). This effect appears to be due to an estrogen-induced activation of the nitric oxide/cGMP/cGMP-dependent protein kinase cascade leading to pro-survival signaling due to phorphorylation of the pro-apoptotic protein $\mathrm{Bcl}-2$ associated death promoter (BAD). Collectively, these findings suggest that the osteocyte is, indeed, an important target for estrogen action and that an increase in osteocyte apoptosis following estrogen deficiency triggers an increase in bone remodeling and resorption. Moreover, given the recent evidence noted above for the osteocyte being an important source of RANKL in bone $(12,13)$, it is possible that osteocyte apoptosis results in an increase in RANKL in the bone microenvironment, perhaps due to RANKL release from the apoptotic osteocytes or via effects of the apoptotic osteocytes on neighboring, viable osteocytes. Clearly, further work is needed to establish just how osteocyte apoptosis might trigger increased bone resorption.

Despite the evidence noted above for estrogen effects on osteocyte apoptosis, a preliminary report by Imai et al. (26) found that deletion of ERa from osteocytes using a Crerecombinase driven by the dentin matrix acidic phosphoprotein 1 (DMP1) promoter failed to have any effect on osteocyte apoptosis or on bone resorption, although the number of osteoblasts on bone surfaces and bone formation rates were clearly reduced. Possible explanations for these surprising findings include compensation for loss of ERa by ER $\beta$, or that incomplete deletion of ERa in osteocytes by the Cre-recombinase led to a sufficient pool of estrogen-sensitive osteocytes, leading to overall effects distinct from those seen following estrogen withdrawal.

\section{Direct and indirect effects of estrogen on osteoclasts}

Consistent with earlier studies showing the presence of estrogen receptors in osteoclasts (27), recent studies have clearly demonstrated that the osteoclast is a direct target for estrogen. Nakamura et al. (28) and Martin-Millan et al. (29) found that osteoclast-specific deletion of ERa (using either a cathepsin-K or lysM Cre, respectively) resulted in decreased trabecular bone mass. This was due, at least in part, to an increase in osteoclast lifespan as a consequence of reduced osteoclast apoptosis. In addition to inducing osteoclast apoptosis, estrogen blocks RANKL/M-CSF-induced activator protein-1-dependent transcription, through a reduction of c-jun activity (reduces c-jun expression and decreases phosphorylation), and suppresses RANKL-induced osteoclast differentiation (30-32). Finally, estrogen inhibits RANKL-stimulated osteoclastic differentiation of human monocytes by inducing ERa binding to a scaffolding protein, BCAR1; the ERa/BCAR1 complex then sequesters TNF receptor associated factor 6 (TRAF6), leading to decreased activation of NFKB and impaired RANKL-induced osteoclastogenesis (33).

In addition to these direct effects on osteoclasts, estrogen also appears to indirectly regulate osteoclast formation and activity. Combined in vitro and in vivo studies have demonstrated that estrogen suppresses RANKL production by osteoblastic, T- and B-cells (34) and also increases production of the decoy receptor for RANKL, osteoprotegerin (OPG) $(35,36)$. Estrogen has also been shown, at least in mouse models, to modulate the production of a 
number of bone-resorbing cytokines, including interleukin (IL)-1, IL-6, tumor necrosis factor-a (TNF-a), macrophage-colony stimulating factor (M-CSF), and prostaglandins (3742). Additionally, the bone resorptive effects of TNF- $a$ are well documented and can be reversed using a soluble type I TNF receptor (43). To evaluate the possible role of IL-1 and TNF- $a$ in mediating increases in bone resorption following estrogen deficiency in humans, Charatcharoenwitthaya et al. (44) administered anakinra or etanercept, specific blockers of IL-1 and TNF-a, respectively, to postmenopausal women following acute estrogen withdrawal. Each of the two blockers reduced the rise in bone resorption markers to about one half of that in controls, consistent with an important role for these immune cytokines in mediating the effect of estrogen deficiency on bone not only in mice, but also in humans.

Pacifici and colleagues $(45,46)$ have proposed that the rapid bone loss following loss of estrogen is due to an expansion of T cells leading to increased TNF-a levels in the bone microenvironment, thereby indirectly enhancing osteoclastogenesis. This group demonstrated that nude mice, which lack T lymphocytes, did not lose bone following ovariectomy (46). Other investigators, however, have found that nude rats (47) and nude RAG2- or TCR-a-deficient mice (all lacking functional T-lymphocytes) lost similar amounts of cancellous bone, following ovariectomy, as wild-type mice (48). Of note, while RAG2 knockout mice lost cortical bone following ovariectomy, nude mice did not. Thus, effects of T-cells in mediating bone loss following estrogen deficiency may be bone compartment specific and may differ between various T-cell deficient models.

Collectively, these data demonstrate that estrogen has numerous direct and indirect effects on osteoclast formation, activity, and lifespan. While the direct effects on osteoclasts mediated by ERa have emerged as perhaps the most dominant, there is considerable evidence for indirect effects of estrogen on osteoclasts mediated through osteoblastic and Tcells.

\section{Estrogen effects on bone formation}

As described earlier, the increase in bone remodeling and in bone resorption in the estrogen deficient state is associated with an increase in bone formation at the tissue level. However, at each BMU, there remains a gap between bone resorption and formation, because the rate of formation is not able to keep up with the rate of resorption, resulting in a net loss of bone. By inference, therefore, sex steroid deficiency is associated with a defect in bone formation. Based on the available evidence, there are currently at least three key mechanisms by which estrogen deficiency may lead to a relative deficit in bone formation through direct effects on osteoblasts: increased apoptosis, increased oxidative stress, and an increase in NF- $\mathrm{kB}$ activity.

Estrogen has been shown to inhibit osteoblast apoptosis and increase osteoblast lifespan (49), thereby increasing the functional capacity of each osteoblast. At a molecular level, the effects of estrogen on reducing osteoblast apoptosis are due to activation of the $\mathrm{Src} / \mathrm{Shc} /$ ERK signaling pathway (49) and downregulation of JNK, which alters the activity of a number of transcription factors, including Elk-1, CCAAT enhancer binding protein- $\beta$ (C/ $\mathrm{EBP} \beta$ ), cyclic adenosine monophosphate-response element binding protein (CREB), and cJun/cFos (50).

A series of studies in mice by Manolagas and colleagues have shown that advancing age increases markers of oxidative stress in bone (51). Products of oxidative stress, including reactive oxygen species (ROS), attenuate osteoblastogenesis and decrease osteoblast/ osteocyte lifespan; conversely, ROS are required for osteoclast generation, function, and survival. Oxidative stress inhibits bone formation, in part, by antagonizing Wnt signaling and diverting $\beta$-catenin from TCF to FoxO-mediated transcription factor binding sites (52). 
Interestingly, the effects of aging on oxidative stress are recapitulated by the loss of estrogen; moreover, effects of estrogen deficiency on bone are reversed by antioxidants (51). Thus, aging and estrogen deficiency may lead to impairment in bone formation through similar mechanisms involving oxidative stress.

Elegant in vivo studies by Chang and colleagues (53) have demonstrated that estrogen deficiency led to a marked increase in NF- $\kappa \mathrm{B}$ activity in osteoblastic cells. In addition, inhibition of NF- $\mathrm{kB}$ resulted in attenuated bone loss following ovariectomy due to a reduced gap between bone resorption and bone formation. NF- $\kappa \mathrm{B}$ inhibition resulted in increased expression of Fos-related antigen 1 (Fra-1), a transcription factor essential for bone matrix formation. Thus, increased NF- $\mathrm{KB}$ activity may mediate, at least in part, the relative deficit in bone formation following estrogen deficiency.

In human studies, estrogen treatment of either postmenopausal women or men with induced hypogonadism (54) also results in a decrease in peripheral blood and bone marrow plasma levels of the potent inhibitor of bone formation, sclerostin. To the extent that changes in bone marrow plasma or peripheral blood sclerostin levels reflect those occurring within osteocytes in bone, estrogen-mediated suppression of sclerostin production may be another possible mechanism for estrogen effects on bone formation, although further studies addressing this issue are clearly needed.

Despite these findings indicating effects of estrogen in maintaining bone formation, recent studies using mice with a colla 1 promoter driven Cre to delete ERa in osteoblastic cells found virtually no skeletal phenotype (55). Deletion of ERa earlier in the osteoblast lineage (using a Prx-Cre) did lead to a reduction in cortical, but not cancellous bone mass (55). These findings contrast with the clear phenotype noted earlier in mice with osteoclastspecific deletion of ERa $(28,29)$. As such, while estrogen clearly modulates bone formation in vivo, the stage at which estrogen may regulate osteoblast function or lifespan, the potential role of ER $\beta$ in modulating or compensating for loss of ERa, and the precise mechanisms by which estrogen deficiency leads to the observed gap between bone resorption and bone formation and ultimately, to bone loss, remain unclear and are active areas of investigation.

A further complexity regarding the effects of estrogen on bone formation is that these effects appear to be bone envelope-specific [reviewed in (56)]. The overall evidence, principally from rodent studies, indicates that estrogens limit periosteal bone expansion but stimulate endosteal bone apposition in females. By contrast, androgens stimulate radial bone expansion in males. In males, optimal radial cortical bone expansion appears to require both androgen receptor (AR) and ERa signaling, with the effects of estrogen/ERa being mediated, at least in part, via interactions with the IGF system (56).

\section{Concluding remarks}

Estrogen clearly has pleiotropic effects on bone metabolism and considerable work over the past several decades by multiple laboratories is beginning to unravel the complexity of estrogen regulation of bone turnover. Figure 2 provides a summary of estrogen effects on the key cells involved in bone metabolism: osteocytes, osteoblasts, osteoclasts, and T-cells, keeping in mind that this is very much a working model and considerable additional details still need to be filled in by ongoing and future work. Estrogen inhibits the activation of bone remodeling, and this effect is most likely mediated via the osteocyte. Estrogen also inhibits bone resorption, largely by direct actions on osteoclasts, although estrogen modulation of osteoblast/osteocyte and T-cell regulation of osteoclast formation and activity are likely also important. Estrogen deficiency is associated with a gap between bone resorption and bone formation. While there are multiple possible mechanisms for this, estrogen effects on 
decreasing osteoblast apoptosis, oxidative stress, and osteoblastic NF- $\kappa \mathrm{B}$ activity appear to be key mediators of the ability of estrogen to maintain bone formation. Understanding each of these mechanisms of the osteoprotective effects of estrogen is likely to lead to new approaches targeting these pathways for the prevention and treatment of osteoporosis.

\section{Acknowledgments}

Supported by research grants NIH AG004875, AR027065, and by the Kogod Center on Aging, Mayo Foundation.

\section{Glossary}

\section{Basic multicellular unit (BMU):}

Bone remodeling:

Bone remodeling compartment (BRC):

Cancellous bone:

Cortical bone:

Endosteal surface:

Osteoblast:

Osteoclast:

Osteocyte:

Periosteal surface:
A structural and functional unit in the skeleton that is responsible for bone remodeling. A BMU includes osteoclasts, osteoblasts, and osteocytes within the bone remodeling cavity.

The process whereby bone is resorbed and then formed, primarily to help repair microcracks that develop in the skeleton.

A structure in bone that consists of the BMU covered by a "canopy" of cells (most probably bone-lining cells).

Also called trabecular bone or spongy bone, is one of two types of tissue that forms bones.

Also called compact bone, is one of the two types of tissues that form bones.

The inner surface of cortical bone.

A cell of mesenchymal origin responsible for forming bone.

A cell of hematopoietic origin responsible for resorbing bone.

A cell embedded within the bone matrix, derived from the osteoblast that helps to orchestrate bone remodeling.

The outer surface of cortical bone.

\section{References}

1. Albright F. Post-menopausal osteoporosis. Trans Assoc Am Physicians. 1940; 55:298-305.

2. Khosla S, Melton LJI, Riggs BL. The unitary model for estrogen deficiency and the pathogenesis of osteoporosis: is a revision needed? J Bone Miner Res. 2011; 26:441-451. [PubMed: 20928874]

3. Lindsay R, Aitkin JM, Anderson JB, Hart DM, MacDonald EB, Clarke AC. Long-term prevention of postmenopausal osteoporosis by oestrogen. Lancet i. 1976:1038-1040.

4. Khosla S, Amin S, Orwoll E. Osteoporosis in men. Endocr Rev. 2008; 29:441-464. [PubMed: 18451258]

5. Falahati-Nini A, Riggs BL, Atkinson EJ, O'Fallon WM, Eastell R, Khosla S. Relative contributions of testosterone and estrogen in regulating bone resorption and formation in normal elderly men. $\mathrm{J}$ Clin Invest. 2000; 106:1553-1560. [PubMed: 11120762]

6. Hannon R, Blumsohn A, Naylor K, Eastell R. Response of biochemical markers of bone turnover to hormone replacement therapy: impact of biological variability. J Bone Miner Res. 1998; 13:11241133. [PubMed: 9661076]

7. Lufkin EG, Wahner HW, O'Fallon WM, Hodgson SF, Kotowicz MA, Lane AW, Judd HL, Caplan RH, Riggs BL. Treatment of postmenopausal osteoporosis with transdermal estrogen. Ann Intern Med. 1992; 117:1-9. [PubMed: 1534476] 
8. Garnero P, Sornay-Rendu E, Chapuy M, Delmas PD. Increased bone turnover in late postmenopausal women is a major determinant of osteoporosis. J Bone Miner Res. 1996; 11:337349. [PubMed: 8852944]

9. Hauge EM, Qvesel D, Eriksen EF, Mosekilde L, Melsen F. Cancellous bone remodeling occurs in specialized compartments lined by cells expressing osteoblastic markers. J Bone Miner Res. 2001; 16:1575-1582. [PubMed: 11547826]

10. Andersen TL, Sondergaard TE, Skorzynska KE, Dagnaes-Hansen F, Plesner TL, Hauge EM, Plesner T, Delaisse J-M. A physical mechanism for coupling bone resorption and formation in adult human bone. Am J Pathol. 2009; 174:239-247. [PubMed: 19095960]

11. Bonewald LF. The amazing osteocyte. J Bone Miner Res. 2011; 26:229-238. [PubMed: 21254230]

12. Xiong J, Onal M, Jilka RL, Weinstein RS, Manolagas SC, O' Brien CA. Matrix-embedded cells control osteoclast formation. Nat Med. 2011; 17:1235-1241. [PubMed: 21909103]

13. Nakashima T, Hayashi M, Fukunaga T, Kurata K, Oh-hora M, Feng JQ, Bonewald LF, Kodama T, Wutz A, Wagner EF, Penninger JM, Takayanagi H. Evidence for osteocyte regulation of bone homeostasis through RANKL expression. Nat Med. 2011; 17:1231-1234. [PubMed: 21909105]

14. Kearns AE, Khosla S, Kostenuik PJ. Receptor activator of nuclear factor kappaB ligand and osteoprotegerin regulation of bone remodeling in health and disease. Endocr Rev. 2008; 29:155192. [PubMed: 18057140]

15. Tang Y, Wu X, Lei W, Pang L, Wan C, Shi Z, Zhao L, Nagy TR, Peng X, Hu J, Feng X, Van Hul W, Cao X. TGF-beta1-induced migration of bone mesenchymal stem cells couples bone resorption with formation. Nat Med. 2009; 15:757. [PubMed: 19584867]

16. Baron R, Ferrari S, Russell RG. Denosumab and bisphosphonates: Different mechanisms of action and effects. Bone. 2011; 48:677-692. [PubMed: 21145999]

17. Zhao C, Irie N, Takada Y, Shimoda K, Miyamoto T, Nishiwaki T, Suda T, Matsuo K. Bidirectional ephrinB2-EphB4 signaling controls bone homeostasis. Cell Metab. 2006; 4:111-121. [PubMed: 16890539]

18. Negishi-Koga T, Shinohara M, Komatsu N, Bito H, Kodama T, Friedel RH, Takayanagi H. Suppression of bone formation by osteoclastic expression of semaphorin 4D. Nat Med. 2011; 17:1473-1480. [PubMed: 22019888]

19. Pederson L, Ruan M, Westendorf JJ, Khosla S, Oursler MJ. Regulation of bone formation by osteoclasts involves Wnt/BMP signaling and the chemokine sphingosine-1-phosphate. Proc Natl Acad Sci USA. 2009; 105:20764-20769. [PubMed: 19075223]

20. Favus MJ. Bisphosphonates for osteoporosis. N Engl J Med. 2010; 363:2027-2035. [PubMed: 21083387]

21. Cummings SR, San Martin J, McClung MR, Siris ES, Eastell R, Reid IR, Delmas P, Zoog HB, Austin MW, A. Kutilek S, Adami S, Zanchetta J, Libanti C, Siddhanti S, Christiansen C, Trial F. Denosumab for prevention of fractures in postmenopausal women with osteoporosis. N Engl J Med. 2009; 361:756-765. [PubMed: 19671655]

22. Tomkinson A, Reeve J, Shaw RW, Noble BS. The death of osteocytes via apoptosis accompanies estrogen withdrawal in human bone. J Clin Endocrinol Metab. 1997; 82:3128-3135. [PubMed: 9284757]

23. Tomkinson A, Gevers EF, Wit JM, Reeve J, Noble BS. The role of estrogen in the control of rat osteocyte apoptosis. J Bone Miner Res. 1998; 13:1243-1250. [PubMed: 9718192]

24. Emerton KB, Hu B, Woo AA, Sinofsky A, Hernandez C, Majesk. Osteocyte apoptosis and control of bone resorption following ovariectomy in mice. Bone. 2010; 46:577-583. [PubMed: 19925896]

25. Marathe N, Rangaswami H, Zhuang S, Boss GR, Pilz RB. Pro-survival effects of 17beta-estradiol on osteocytes are mediated by NO/cGMP via differential actions of PKG I and II. J Biol Chem. 2011 In press:http://www.jbc.org/content/early/2011/2011/2022/jbc.M2111.294959.

26. Imai Y, Bonewald LF, Kondoh S, Kato S. Estrogen receptor alpha expression in osteocytes is necessary to maintain normal bone mineral density and reduce bone loss due to unloading. J Bone Miner Res. 2011; 26(Suppl 1) http://www.abstracts2view.com/asbmr/view.php? nu=ASBMR11L_A11007189-11007129 (Abstract).

27. Oursler MJ, Osdoby P, Pyfferoen J, Riggs BL, Spelsberg TC. Avian osteoclasts as estrogen target cells. Proc Natl Acad Sci USA. 1991; 88:6613-6617. [PubMed: 1907373] 
28. Nakamura T, Imai Y, Matsumoto T, Sato S, Takeuchi K, Igarashi K, Harada Y, Azuma Y, Krust A, Yamamoto Y, Nishina H, Takeda S, Takayanagi H, Metzger D, Kanno J, Takaoka K, Martin TJ, Chambon P, Kato S. Estrogen prevents bone loss via estrogen receptor alpha and induction of fas ligand in osteoclasts. Cell. 2007; 130:811-823. [PubMed: 17803905]

29. Martin-Millan M, Almeida M, Ambrogini E, Han L, Zhao H, Weinstein RS, Jilka RL, O' Brien CA, Manolagas SC. The estrogen receptor-alpha in osteoclasts mediates the protective effects of estrogens on cancellous but not cortical bone. Mol Endocrinol. 2010; 24:323-334. [PubMed: 20053716]

30. Shevde NK, Bendixen AC, Dienger KM, Pike JW. Estrogens suppress RANK ligand-induced osteoclast differentiation via a stromal cell independent mechanism involving c-Jun repression. Proc Natl Acad Sci USA. 2000; 97:7829-7834. [PubMed: 10869427]

31. Huber DM, Bendixen AC, Pathrose P, Srivastava S, Dienger KM, Shevde NK, Pike JW. Androgens suppress osteoclast formation induced by RANKL and macrophage-colony stimulating factor. Endocrinology. 2001; 142:3800-3808. [PubMed: 11517156]

32. Srivastava S, Toraldo G, Weitzmann MN, Cenci S, Ross FP, Pacifici R. Estrogen decreases osteoclast formation by down-regulating receptor activator of NF-kB ligand (RANKL)-induced JNK activation. J Biol Chem. 2001; 276:8836-8840. [PubMed: 11121427]

33. Robinson LJ, Yaroslavskity BB, Griswold RD, Zadorozny EV, Guo L, Tourkova IL, Blair HC. Estrogen inhibits RANKL-stimulated osteoclastic differentiation of human monocytes through estrogen and RANKL-regulated interaction of estrogen receptor alpha with BCAR1 and Traf6. Exp Cell Res. 2009; 315:1287-1301. [PubMed: 19331827]

34. Eghbali-Fatourechi G, Khosla S, Sanyal A, Boyle WJ, Lacey DL, Riggs BL. Role of RANK ligand in mediating increased bone resorption in early postmenopausal women. J Clin Invest. 2003; 111:1221-1230. [PubMed: 12697741]

35. Hofbauer LC, Khosla S, Dunstan CR, Lacey DL, Spelsberg TC, Riggs BL. Estrogen stimulates gene expression and protein production of osteoprotegerin in human osteoblastic cells. Endocrinology. 1999; 140:4367-4370. [PubMed: 10465311]

36. Khosla S, Atkinson EJ, Dunstan CR, O'Fallon WM, Riggs BL. Estrogen and testosterone have opposite effects on circulating OPG levels following induction of hypogonadism and aromatase inhibition in normal elderly men: potential mechanism for differential effects of estrogen versus testosterone on bone resorption. J Bone Miner Res. 2001; 16(Suppl 1):S146.

37. Manolagas SC, Jilka RL. Bone marrow, cytokines, and bone remodeling: Emerging insights into the pathophysiology of osteoporosis. N Engl J Med. 1995; 332:305-311. [PubMed: 7816067]

38. Pacifici R, Brown C, Puscheck E, Friedrich E, Slatopolsky E, Maggio D, McCracken R, Avioli LV. Effect of surgical menopause and estrogen replacement on cytokine release from human blood mononuclear cells. Proc Natl Acad Sci USA. 1991; 88:5134-5138. [PubMed: 2052592]

39. Tanaka S, Takahashi N, Udagawa N, Tamura T, Akatsu T, Stanley ER, Kurokawa T, Suda T. Macrophage colony-stimulating factor is indispensable for both proliferation and differentiation of osteoclast progenitors. J Clin Invest. 1993; 91:257-263. [PubMed: 8423223]

40. Kimble RB, Vannice JL, Bloedow DC, Thompson RC, Hopfer W, Kung VT, Brownfield C, Pacifici R. Interleukin-1 receptor antagonist decreases bone loss and bone resorption in ovariectomized rats. J Clin Invest. 1994; 93:1959-1967. [PubMed: 8182127]

41. Ammann P, Rizzoli R, Bonjour J, Bourrin S, Meyer J, Vassalli P, Garcia I. Transgenic mice expressing soluble tumor necrosis factor-receptor are protected against bone loss caused by estrogen deficiency. J Clin Invest. 1997; 99:1699-1703. [PubMed: 9120014]

42. Kimble RB, Srivastava S, Ross FP, Matayoshi A, Pacifici R. Estrogen deficiency increases the ability of stromal cells to support murine osteoclastogenesis via an interleukin-1-and tumor necrosis factor-mediated stimulation of macrophage colony-stimulating factor production. J Biol Chem. 1996; 271:28890-28897. [PubMed: 8910536]

43. Kitazawa R, Kimble RB, Vannice JL, Kung VT, Pacifici R. Interleukin-1 receptor antagonist and tumor necrosis factor binding protein decrease osteoclast formation and bone resorption in ovariectomized mice. J Clin Invest. 1994; 94:2397-2406. [PubMed: 7989596] 
44. Charatcharoenwitthaya N, Khosla S, Atkinson EJ, McCready LK, Riggs BL. Effect of blockade of TNF-a and interleukin-1 action on bone resorption in early postmenopausal women. $\mathrm{J}$ Bone Miner Res. 2007; 22:724-729. [PubMed: 17295604]

45. Roggia C, Gao Y, Cenci S, Weitzmann MN, Toraldo G, Isaia G, Pacifici R. Up-regulation of TNFproducing $\mathrm{T}$ cells in the bone marrow: a key mechanism by which estrogen deficiency induces bone loss in vivo. Proc Natl Acad Sci U S A. 2001; 98:13960-13965. [PubMed: 11717453]

46. Cenci S, Weitzmann MN, Roggia C, Namba N, Novack D, Woodring J, Pacifici R. Estrogen deficiency induces bone loss by enhancing T-cell production of TNF-a. J Clin Invest. 2000; 106:1229-1327. [PubMed: 11086024]

47. Sass DA, Liss T, Bowman AR, Rucinski B, Popoff SN, Pan Z, Ma YF, Epstein S. The role of the T-lymphocyte in estrogen deficiency osteopenia. J Bone Miner Res. 1997; 12:479-486. [PubMed: 9076592]

48. Lee SK, Kadono Y, Okada F, Jacquin C, Koczon-Jareml B, Adams DJ, Aguila HL, Choi Y, Lorenzo JA. T lymphocyte-deficient mice lose trabecular bone mass with ovariectomy. J Bone Miner Res. 2006; 21:1704-1712. [PubMed: 17002560]

49. Kousteni S, Bellido T, Plotkin LI, O'Brien CA, Bodenner DL, Han L, Han K, DiGregorio GB, Katzenellenbogen JA, Katzenellenbogen BS, Roberson PK, Weinstein RS, Jilka RL, Manolagas SC. Nongenotropic, sex-nonspecific signaling through the estrogen or androgen receptors: dissociation from transcriptional activity. Cell. 2001; 104:719-730. [PubMed: 11257226]

50. Kousteni S, Han L, Chen JR, Almeida M, Plotkin LI, Bellido T, Manolagas SC. Kinase-mediated regulation of common transcription factors accounts for the bone-protective effects of sex steroids. J Clin Invest. 2003; 111:1651-1664. [PubMed: 12782668]

51. Almeida M, Martin-Millan M, Plotkin LI, Stewart SA, Roberson PK, Kousteni S, O'Brien CA, Bellido T, Parfitt AM, Weinstein RS, Jilka RL, Manolagas SC. Skeletal involution by ageassociated oxidative stress and its acceleration by loss of sex steroids. J Biol Chem. 2007; 282:27285-27297. [PubMed: 17623659]

52. Manolagas SC, Almeida M. Gone with the Wnts: beta-catenin, t-cell factor, forkhead box O, and oxidative stress in age-dependent diseases of bone, lipid, and glucose metabolism. Mol Endocrinol. 2007; 21:2605-2614. [PubMed: 17622581]

53. Chang J, Wang Z, Tang E, Fan Z, McCauley L, Franceschi R, Guan K, Krebsbach PH, Wang C-Y. Inhibition of osteoblastic bone formation by nuclear factor-kappaB. Nat Med. 2009; 15:682-689. [PubMed: 19448637]

54. Modder UIL, Clowes JA, Hoey K, Peterson JM, McCready L, Oursler MJ, Riggs BL, Khosla S. Regulation of circulating sclerostin levels by sex steroids in women and men. J Bone Miner Res. 2011; 26:27-34. [PubMed: 20499362]

55. Iyer S, Bartell S, Warren A, Han L, Martin-Millan M, Ambrogini E, Xiong J, Weinstein RS, Jilka RL, O' Brien CA, Almeida M, Manolagas SC. ERalpha-deletion from osteoblast progenitors abolishes the protective effect of estrogens on cortical bone mass in both female and male mice. $\mathrm{J}$ Bone Miner Res. 2011; 26(Suppl 1) http://www.abstracts2view.com/asbmr/view.php? nu=ASBMR11L_A11006290-11006103 (Abstract).

56. Callewaert F, Sinnesael M, Gielen E, Boonen S, Vanderschueren D. Skeletal sexual dimorphism: relative contribution of sex steroids, GH-IGF1, and mechanical loading. Journal of Endocrinol. 2010; 207:127-134. [PubMed: 20807726] 


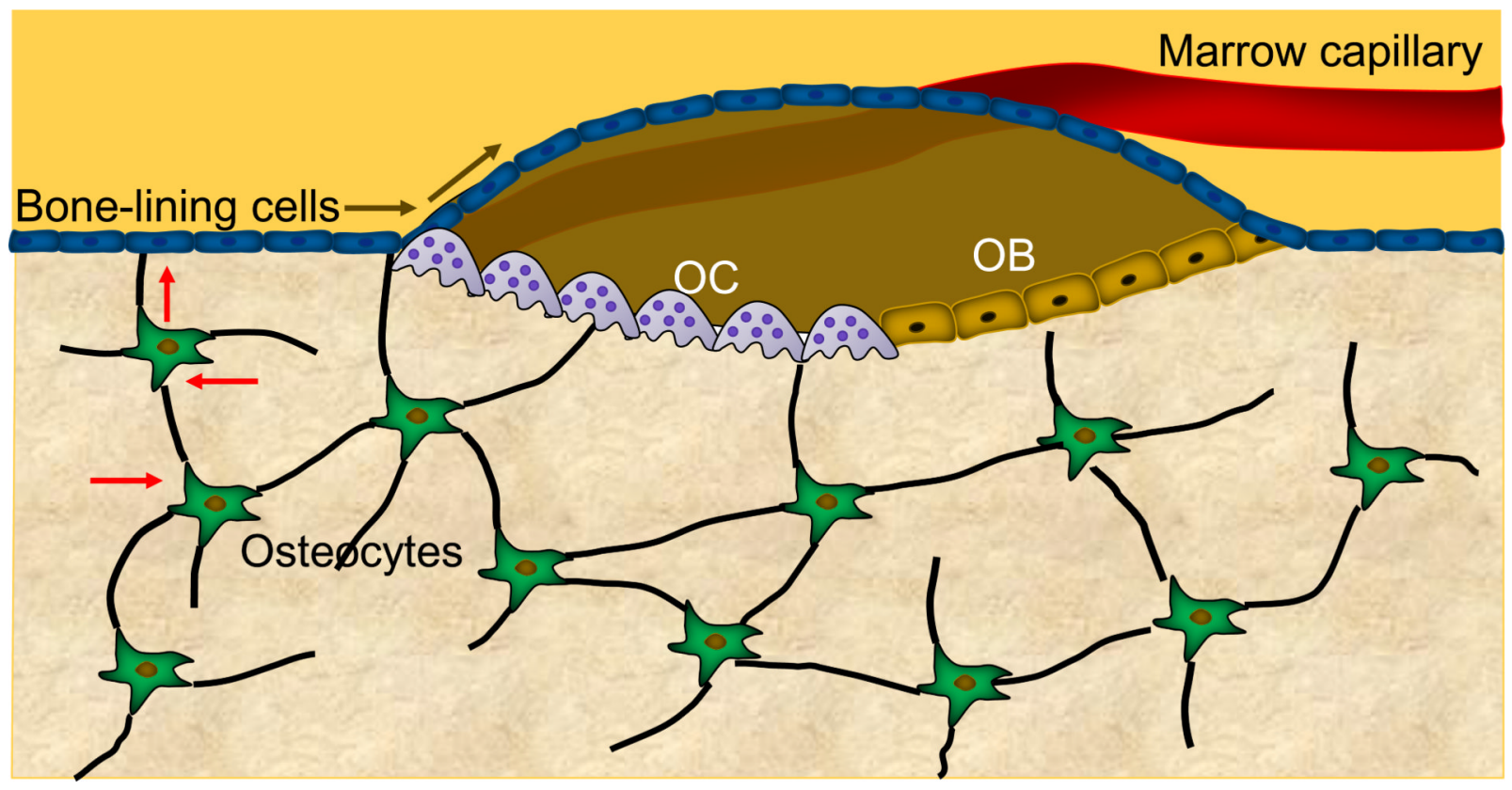

Figure 1. Schematic of the bone remodeling compartment

The bone remodeling compartment (BRC) comprises the cells constituting the basic multicellular unit (BMU) - specifically osteoclasts (OCs), osteoblasts (OBs), and osteocytes - as well as the canopy of bone-lining cells and the associated capillary. Shown also are connections between the osteocyte network, surface bone-lining cells, and the BRC. All cells in this network are connected with gap junctions, which might provide a pathway (block arrows) by which signals generated by osteocytes deep within the bone reach the surface and elicit remodeling events by OCs and OBs. Note also the potential direct physical contact between OCs and OBs, which would allow for signaling between these cells. 


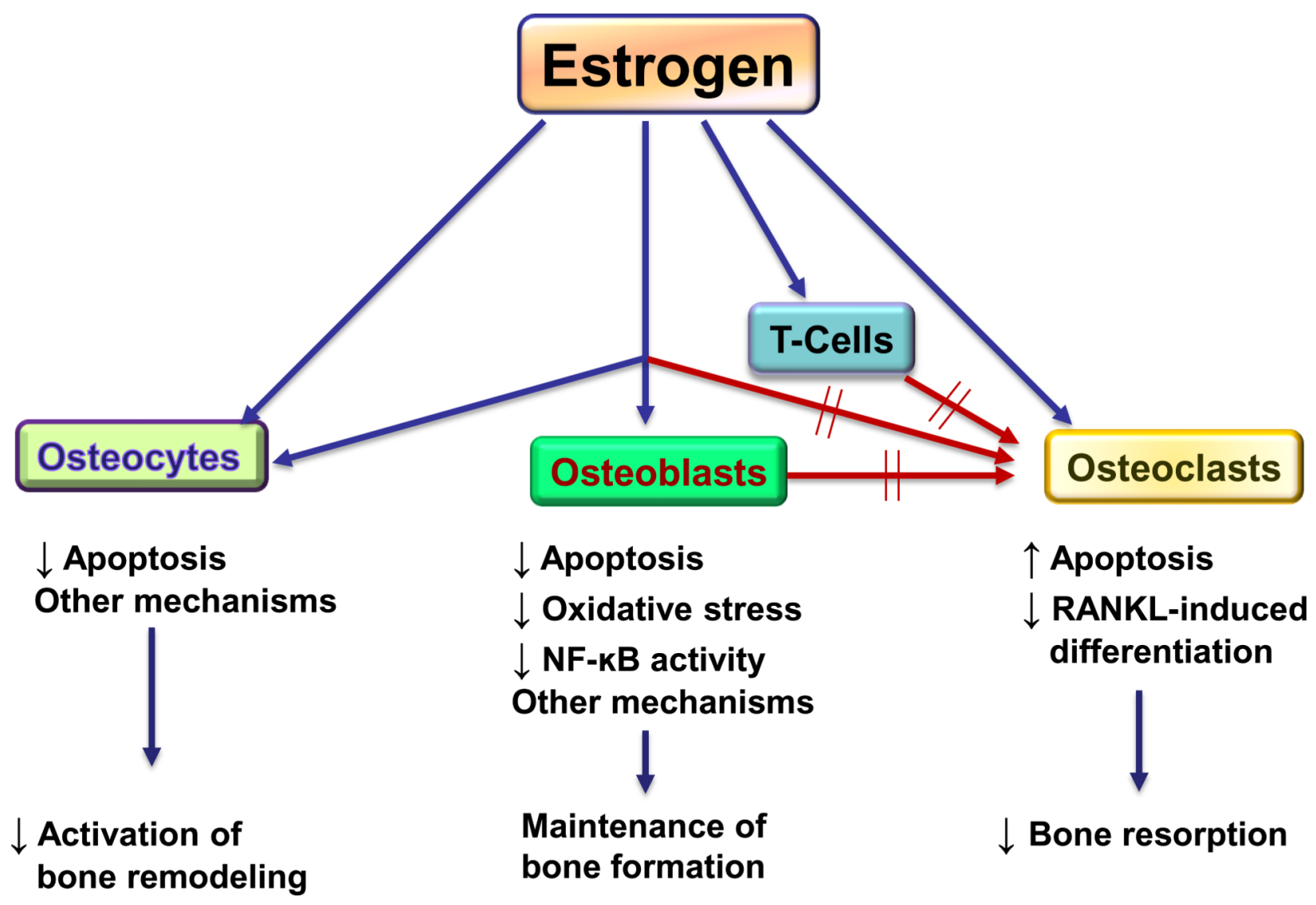

Figure 2. Working model for estrogen regulation of bone turnover via effects on osteocytes, osteoblasts, osteoclasts, and T-cells

The main effect of estrogen is to inhibit bone remodeling, likely via the osteocyte. Estrogen also inhibits bone resorption, principally by directs effects on osteoclasts, although effects of estrogen on osteoblast/osteocyte and T-cell regulation of osteoclasts likely also play a role. Estrogen deficiency is associated with a gap between bone resorption and bone formation, likely due to the loss of the effects of estrogen on decreasing osteoblast apoptosis, oxidative stress, osteoblastic NF- $\kappa$ B activity, and perhaps other, as yet undefined, mechanisms. 